\title{
The use, nature and purposes of measurement in intermediate-level occupations
}

\author{
Arthur Bakker • Monica Wijers • Vincent Jonker • \\ Sanne Akkerman
}

Accepted: 24 March 2011 / Published online: 16 April 2011

(C) The Author(s) 2011. This article is published with open access at Springerlink.com

\begin{abstract}
To provide a basis for thinking through how measurement can be taught in schools, this paper analyses the use, nature and purposes of measurement in intermediate-level work, i.e. occupations for which a school-level qualification is required, but not a bachelor degree or higher. In the Netherlands, senior secondary vocational education (MBO) prepares its students (aged 16+) for intermediate-level work. An initial analysis of the use and purposes of measurement was based on competence descriptions for $549 \mathrm{MBO}-$ level occupations, and complemented with analyses of measurement carried out by opticians and lab technicians. There is more reference to measurement in the technology and engineering sector than in other sectors. In terms of the nature of measurement, we observed that occupational measurement has intricate connections to arithmetic, geometry, data analysis, or science; and measurement at work is often, but not always, mediated by digital technologies. The purposes of measurement in intermediate-level occupations can be categorized as meeting quality standards, making something fit (furniture, textile, assembly), monitoring, safety, and problem solving. Last, some implications for mathematics, science and vocational education are discussed. For example, many MBO teachers prefer to start with mechanical tools to give students the opportunities to learn about what happens in the 'black boxes' of digital technologies.
\end{abstract}

\footnotetext{
A. Bakker $(\bowtie) \cdot$ M. Wijers · V. Jonker · S. Akkerman Freudenthal Institute for Science and Mathematics Education, Utrecht University, Princetonplein 5,

3584 CC Utrecht, The Netherlands

e-mail: a.bakker4@uu.nl

URL: http://www.fi.uu.nl/ arthur
}

Keywords Measurement - Occupations · Tool mediation · Vocational education . Workplace mathematics

\section{Introduction}

The purpose of this paper is to provide insight into the use, nature and purposes of measurement within the context of intermediate-level work, i.e. occupations for which a schoollevel qualification is required, but not a bachelor degree or higher. In essence, measurement is the assignment of a numerical value to an attribute of an object (Bright, Jordan, Malloy, \& Watanabe, 2005). Thus, measurement leads to numbers, and mathematics can assist in manipulating these numbers (Crosby, 1997). Measurement is always mediated by tools: Where farmers and traders in the ancient past used body parts to measure land and cloth (Dilke, 1987), modern workers use a wide range of tools, ranging from cheap old-fashioned mechanical ones to expensive modern digital technologies.

Measures and measurement are common in many occupations. The Cockcroft report on the mathematical needs for employment concluded that:

It is possible to summarise a very large part of the mathematical needs of employment as a feeling for measurement. This implies very much more than an ability to calculate, to estimate and to use measuring instruments, although all of these are part of it. It implies an understanding of the nature and purposes of measurement, of the many different methods of measurement which are used and of the situations in which each is found; it also implies an ability to interpret measurements expressed in a variety of ways. (Cockcroft, 1982, para. 85, our emphasis) 
What students should learn is a question that is neglected in research on competence-based vocational education in general (Van den Berg \& De Bruijn, 2009) and too often ignored by researchers in mathematics education specifically (Van den Heuvel-Panhuizen, 2005). With this paper, we aim to provide a resource for those who try to keep schooling up to date (Smith, 1999), in this case schooling in measurement. For example, Adams and Harrell (2003) observed that school measurement tends to be more formal and paper-and-pencil based, while employees often use estimation. Regularly revisiting the what-question is important not only in view of such differences between school and workplace mathematics, but also with changes in society in mind.

The differences between cognition 'in captivity' and cognition 'in the wild' (Hutchins, 1995) can be big (e.g., Lave, 1988; Nunes, Schliemann, \& Carraher, 1993). Where school can focus on clean examples of mathematical ideas, mathematical ideas at work are always situated abstractions (Noss \& Hoyles, 1996) - they are part of a web of specific constraints and requirements, and driven by global competition and efficiency (Bakker, Kent, Derry, Noss, \& Hoyles, 2008).

Change in the nature of measurement at work is likely due to the trend of automation and computerization. As elaborated in the research by Hoyles, Noss, Kent, and Bakker (2010), mathematical knowledge at work is increasingly mediated by digital technologies, although it is not yet clear to what extent this is the case. And in line with insights from situated cognition (Greeno, 1998), Kaiser and Willander (2005, p. 79) observe that "it is questionable whether mathematical skills can be separated from the context of the social dimension of action and from the purposes and goals of the activity in which they are embedded." These observations, from Cockcroft to Kaiser and Willander, lead us to ask: What are the use, nature and purposes of measurement in intermediate-level occupations? The answer provides a basis to think through implications for the teaching of measurement.

\section{Intermediate-level work}

In the Netherlands, the sector that prepares students for intermediate-level work is senior secondary vocational education (MBO). With 506,300 students (in 2010), it is the largest, and most diverse, sector of education in our country. More students attend secondary vocational education than secondary general education, and about $65 \%$ of Dutch employees have attended MBO. The educational programs are divided across four sectors:

1. agriculture, food technology and fisheries (5\% of the students);
2. health care, social care, welfare and sports (32\%);

3 . economics and business $(33 \%)$;

4. engineering and technology $(30 \%)$.

$\mathrm{MBO}$ education is provided at four qualification levels:

- level 1: assistant training (programs take 6-12 months);

- level 2: basic vocational training (2-3 years);

- level 3: professional training (2-4 years);

- level 4: middle management training and specialist training (3-4 years).

Examples of occupations in each sector and level are provided in Table 1.

The MBO occupations are described in so-called qualification files, Ministry approved documents formulating the competencies required to pass the exams. These files-an updated set of 237 for the school year 2010-2011 - were produced in the Centres of Expertise on vocational education in the Netherlands, together with stakeholders from education and the labor market. These files mostly describe two or three occupations at different levels, from assistant to all-round. For example, the car mechanic file describes three occupations: car mechanic (level 2), first car mechanic (level 3) and technical car specialist (level 4). The 237 files thus describe a total of 627 occupations. Every occupation is described in terms of core tasks and work processes, which are detailed in competence descriptions and related to underlying knowledge and skills lists. These overviews are written to help teachers develop educational programs and employers to find evidence for students' competencies.

Over the past years, the qualification files have increasingly become uniform in terms of how competencies and underlying knowledge and skills are described. The current similarity of the structure and style of these files allows for a cross-sector comparison.

\section{Methods}

\subsection{Search queries in the qualification files}

In order to address the research question, we draw on various resources. With respect to how measurement is used in intermediate-level occupations, we intended to get an image of the prominence of measurement in the different sectors of work. For this we used the qualification files as formalized descriptions of competencies for a starting professional practitioner. We first counted competence descriptions - the most detailed unit in the qualification files - that explicitly mention measurement-related terms. In three rounds of trying and testing a query on a random sample of 20 descriptions, we developed a search 
Table 1 Examples of intermediate-level occupations arranged by MBO sectors and levels

\begin{tabular}{|c|c|c|c|c|}
\hline & $\begin{array}{l}\text { Agriculture/fisheries/food } \\
\text { technology }\end{array}$ & $\begin{array}{l}\text { Healthcare/welfare/ } \\
\text { sports }\end{array}$ & Economics/business & $\begin{array}{l}\text { Technology/ } \\
\text { engineering }\end{array}$ \\
\hline $\begin{array}{l}\text { Level 4: Middle management } \\
\text { specialist training }\end{array}$ & $\begin{array}{l}\text { Entrepreneur florist } \\
\text { Breeding manager }\end{array}$ & $\begin{array}{l}\text { Dental assistant } \\
\text { Head of kitchen } \\
\text { (Cook) } \\
\text { Care and nursing } \\
\text { Welfare worker } \\
\text { Audiologist } \\
\text { All-round lab } \\
\text { technician }\end{array}$ & $\begin{array}{l}\text { Assistant accountant } \\
\text { Salary administrator } \\
\text { Manager travel agency } \\
\text { Library assistant } \\
\text { Patissier }\end{array}$ & $\begin{array}{l}\text { Technical car specialist } \\
\text { Software application } \\
\text { designer }\end{array}$ \\
\hline Level 3: Professional training & $\begin{array}{l}\text { Senior florist } \\
\text { Employee animal care }\end{array}$ & $\begin{array}{l}\text { Hairdresser } \\
\text { Independent cook } \\
\text { Employee social care }\end{array}$ & $\begin{array}{l}\text { Bookkeeping assistant } \\
\text { Travel sales agent } \\
\text { All-round baker }\end{array}$ & $\begin{array}{l}\text { First car mechanic } \\
\text { All-round desktop } \\
\text { publisher }\end{array}$ \\
\hline Level 2: Basic vocational training & $\begin{array}{l}\text { Junior florist } \\
\text { Employee biodynamic } \\
\text { farm }\end{array}$ & $\begin{array}{l}\text { Cook } \\
\text { Aqua and leisure } \\
\text { assistant } \\
\text { Care helper } \\
\text { Sport and exercise } \\
\text { supervisor } \\
\text { Lab assistant }\end{array}$ & $\begin{array}{l}\text { Receptionist } \\
\text { Sales agent (bikes, fuel } \\
\text { station, shops) } \\
\text { Basic prepress operator } \\
\text { Facility services employee } \\
\text { Baker }\end{array}$ & $\begin{array}{l}\text { Car mechanic } \\
\text { Desktop publisher } \\
\text { Painter } \\
\text { Bricklayer }\end{array}$ \\
\hline Level 1: Training to assistant level & Assistant animal care & $\begin{array}{l}\text { Health care assistant } \\
\text { Host }\end{array}$ & $\begin{array}{l}\text { Assistant logistics } \\
\text { Hospitality assistant }\end{array}$ & $\begin{array}{l}\text { Labor market qualified } \\
\text { assistant }\end{array}$ \\
\hline
\end{tabular}

query using terms such as 'measurement,' 'measuring,' 'measure(s)' (meting, meten, maat/maten) excluding words with 'maat' in them that have nothing to do with measurement (e.g., 'klimaat,' meaning climate) and measurement-related phrases that were only metaphorical (e.g., 'zorg op maat,' meaning 'care fit to the patient').

To identify the purposes of measurement, we generated categories from reading a random sample of 50 competence descriptions involving measurement. Many of these descriptions had the form: "The <occupational worker $>$ does $<$ activity involving measurement $>$ in order to $<$ purpose $>$." This allowed us to relate use of measurement to its purposes (e.g., measurement for quality, measurement for problem solving). We tested the categories on two other random samples of 50 descriptions. This did not lead to extra categories describing common purposes of measurement, on the basis of which we concluded that we reached saturation (Creswell, 1998).

\subsection{Qualitative study of occupations}

To complement the aforementioned approach (Sect. 3.1) focusing on formalized descriptions of measurement in occupations (identifying mathematics for work) and gain a more qualitative sense of the use, nature and purposes of measurement as situated in a work practice (identifying mathematics in work), we consider data that we have previously gathered about the mathematical work of opticians and lab technicians (Bakker, Wijers, \& Akkerman, 2010). These are occupations in which measurement is important in different ways. In laboratory education, we carried out interviews with 35 apprentices and 11 teachers in 4 laboratory schools, as well as with managers, and workplace supervisors in 8 companies. We also analyzed workplace documents and made observations in five laboratories (ranging from an hour to a full day per visit). For the optician example, we interviewed an optics teacher who has a background in chemistry. We also investigated the training of operational technicians in the oil refineries area near the Port of Rotterdam.

\section{Results}

4.1 The use of measurement reflected in the qualification files

Of the 237 qualification files, 27 belonged to two or more sectors. For a fair comparison of the use of measurement in different sectors, we narrowed down to 210 qualification files that were only part of one sector. This reduced set comprised 549 occupations.

Table 2 provides an overview of numbers of measurement-related descriptions divided by the number of all 
Table 2 Number of measurement-related descriptions divided by number of all competence descriptions found in 210 qualification files by sector and level (percentages in parentheses)

\begin{tabular}{|c|c|c|c|c|c|}
\hline & $\begin{array}{l}\text { Agriculture, fisheries } \\
\text { and food technology }\end{array}$ & $\begin{array}{l}\text { Care and } \\
\text { welfare }\end{array}$ & $\begin{array}{l}\text { Economy } \\
\text { and business }\end{array}$ & $\begin{array}{l}\text { Engineering } \\
\text { and technology }\end{array}$ & $\begin{array}{l}\text { Total by } \\
\text { level (\%) }\end{array}$ \\
\hline Level 1 & - & $0 / 16(0 \%)$ & $11 / 150(7 \%)$ & $12 / 229(5 \%)$ & 5.8 \\
\hline Level 2 & $3 / 402(1 \%)$ & $0 / 108(0 \%)$ & $38 / 2,379(2 \%)$ & $147 / 1,475(10 \%)$ & 2.0 \\
\hline Level 3 & $6 / 1,780(0 \%)$ & $52 / 386(1 \%)$ & $81 / 4,581(2 \%)$ & $223 / 2,665(8 \%)$ & 3.3 \\
\hline Level 4 & $23 / 2,270(1 \%)$ & $51 / 1,287(4 \%)$ & $229 / 8,523(3 \%)$ & $130 / 2,949(4 \%)$ & 2.9 \\
\hline Total by sector & $1 \%$ & $3 \%$ & $2.3 \%$ & $7 \%$ & 3.8 \\
\hline
\end{tabular}

competence descriptions found in qualification files by sector and level (percentages in parentheses). This information allows us to compare both absolute and relative frequencies of measurement-related descriptions. The figures suggest that measurement is more prominent in the technology and engineering sector than in other sectors, both in relative (7\%) and absolute numbers (in particular in building, infrastructure and aviation). We were surprised by the low numbers in the food and fisheries sector. In the food files, measurement is only mentioned at level 4 ; in the fisheries files, it is mentioned at levels 2, 3 and 4. We had not expected to find higher numbers in care and welfare than in business and economics, but tracking down the files with higher numbers revealed that about $80 \%$ of the number of measurement-related descriptions stem from occupations in the technical care sector (such as lab technicians in hospitals and assistants of doctors, dentists and pharmacists). In other care, welfare and sports-related occupations, measurement is used much less.

What further struck us were the higher figures for lower levels in the economic and technology sectors. Further scrutiny revealed that the lower level occupations in economy and business with high percentages of measurement-related descriptions were related to fashion, interior, carpet, and textile-where measurement can be expected to be important. In the engineering and technology sector, lower level workers do more of the measurement activities themselves, while the level-4 workers have management positions. This might explain the lower percentage (4\%) of level 4 in the engineering and technology sector.

When interpreting these figures, we should note that competencies are formulated in general terms (e.g., "care for quality") with on the whole little specific attention for mathematical knowledge required. Therefore, we assume the query in the competence descriptions does not yield all occupations in which measurement is actually used. Hence, we think measurement is used much more than what we found in our initial query. If we further take into account that Table 2 provides percentages of measurement-related competence descriptions as part of all competence descriptions, considering not just mathematics but what the whole jobs entail, measurement actually turns out to be quite important in intermediate-level occupations.

To give a more qualitative sense of how measurement is used in different occupations, we randomly picked two measurement-related competencies for each of the four sectors (Table 3). These examples also give some insight into the purposes of measurement. They refer to quality or standards (examples $1,5,8,9)$, making something fit $(2,4)$, safety (3) and problem solving (7)—categories discussed in more detail in the next section.

\subsection{Purposes of measurement reflected}

in the qualification files

The categorization process described in Sect. 3.1 led to different purposes of measurement. Table 4 provides an overview of these purposes and gives examples. The purposes of measurement can be categorized as measurement being in the service of quality, monitoring, safety, making something fit (design, assembly), and problem solving. We should note that measurement sometimes serves multiple purposes. For example, a lab technician may measure the concentration of potassium in drinking water at a water bottling plant in order to monitor the production process, for quality control and safety. The purpose mentioned most frequently was quality, followed by monitoring, making something fit and solving problems. Safety was mentioned much less frequently.

As mentioned before, the study of the qualification files gives an overview of the use and purposes of measurement in intermediate-level occupations. However, complementary studies are required for studying the nature of measurement at work. We focused on lab technicians and opticians-two occupations in which measurement is important, though in different ways. These qualitative analyses also allow us to draw some educational implications.

\subsection{Measurement of concentrations by lab technicians}

According to the qualification file, a lab technician at level 4 carries out measurements as part of mostly standardized 
Table 3 Examples of competence descriptions related to measurement randomly chosen from each sector

\begin{tabular}{|c|c|c|c|}
\hline Ex. & Competence description (search terms in bold) & Qualification file and sector & Level \\
\hline 1 & $\begin{array}{l}\text { He samples and takes measurements for product and process control in } \\
\text { skilled and accurate ways taking into account the vulnerability and } \\
\text { decay of food }\end{array}$ & $\begin{array}{l}\text { Assistant food and environment } \\
\text { Food technology }\end{array}$ & 1 \\
\hline 2 & $\begin{array}{l}\text { The carpenter interprets the construction drawing and understands the } \\
\text { structure and shape of the product. He chooses and manipulates the } \\
\text { equipment for measuring and assembling the various parts correctly }\end{array}$ & $\begin{array}{l}\text { Carpenter } \\
\text { Economics }\end{array}$ & 2 \\
\hline 3 & $\begin{array}{l}\text { The lab assistant uses equipment for analysis and uses chemicals } \\
\text { according to regulations. He treats them in a proper and careful way to } \\
\text { ensure a good condition of the equipment and to produce reliable } \\
\text { measurement results }\end{array}$ & $\begin{array}{l}\text { Lab assistant } \\
\text { Care }\end{array}$ & 2 \\
\hline 4 & $\begin{array}{l}\text { The metal worker accurately assembles different parts of the product in } \\
\text { order to finalize the production process according to quality } \\
\text { requirements in terms of measure (length, width, height, design), } \\
\text { number, and delivery time }\end{array}$ & $\begin{array}{l}\text { Metal worker } \\
\text { Technology }\end{array}$ & 3 \\
\hline 5 & $\begin{array}{l}\text { The First mate/marine engineer of small fishing boats professionally } \\
\text { recognizes the fish based on size and species and sorts them into the } \\
\text { correct bins. Discards are thrown back into the water and in case of } \\
\text { doubt he will use a measuring board }\end{array}$ & $\begin{array}{l}\text { First mate/marine engineer small } \\
\text { fishing boats } \\
\text { Fisheries and food technology }\end{array}$ & 3 \\
\hline 6 & $\begin{array}{l}\text { The sport and activity coach collects sufficient relevant data about the } \\
\text { performance of the SA-participant, for instance through observations } \\
\text { and measurements and judges, based on these data, whether the SA- } \\
\text { participant meets the expected standards, allowing the (social) skill } \\
\text { level of the SA-participant to be determined correctly and any skill } \\
\text { qualifications can be issued appropriately }\end{array}$ & $\begin{array}{l}\text { Sport and activity coach } \\
\text { Care }\end{array}$ & 4 \\
\hline 7 & $\begin{array}{l}\text { The aircraft technician examines possible causes of malfunction, verifies } \\
\text { them, analyzes the results of the measurements, and draws logical } \\
\text { conclusions on the fault so as to locate and analyze the problem } \\
\text { adequately }\end{array}$ & $\begin{array}{l}\text { Aircraft technician } \\
\text { Technology }\end{array}$ & 4 \\
\hline 8 & $\begin{array}{l}\text { The senior logistics timber selects the measurement tools suitable for } \\
\text { identifying stocks. He controls the quality standards during inventory of } \\
\text { the appropriate wooden materials and makes efficient use of the } \\
\text { measurement tools }\end{array}$ & $\begin{array}{l}\text { Senior logistics manager for timber } \\
\text { Economics }\end{array}$ & 4 \\
\hline
\end{tabular}

Table 4 Purposes of measurement exemplified in competence descriptions

\begin{tabular}{ll}
\hline Purpose & Example of a competence description \\
\hline Quality & $\begin{array}{l}\text { The chipper processes the material in a systematic way by alternating the chipping with } \\
\text { intermediate measurements to ensure that the final product meets the quality } \\
\text { requirements } \\
\text { The food operational technician checks and judges measurements based on } \\
\text { specifications } \\
\text { The sales employee gas station works systematically and orderly and carefully measures } \\
\text { fuel in order to guarantee safety } \\
\text { The furniture upholsterer stitches the coating material taking into account the } \\
\text { characteristics of the material so that the coating is suitable for the furniture } \\
\text { The aircraft technician examines possible causes of malfunction, verifies them, analyzes } \\
\text { the results of the measurements, and draws logical conclusions on the fault so as to } \\
\text { locate and analyze the problem adequately }\end{array}$ \\
Problem solving &
\end{tabular}

and routine analyses. Three core tasks are described in the file: preparing analyses; performing analyses; supporting research and education. In the core task of performing analyses, three out of seven work processes explicitly involve measurement: using basic techniques; carrying out specific analyses; assessing and reporting measurement values.

To illustrate how measurement is part of the chemical analysis, we describe a typical measurement procedure in chemical laboratories. The purpose of this analysis is to 


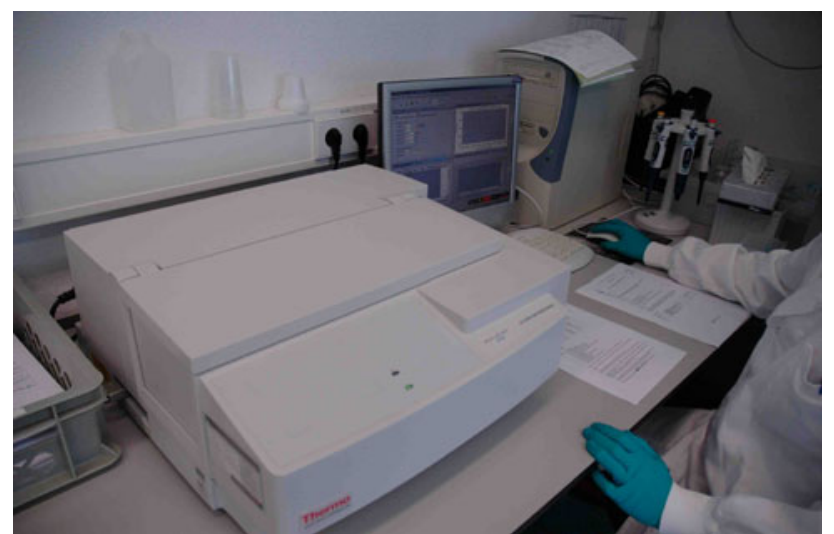

Fig. 1 Spectrophotometer linked to a computer

determine the concentration of a substance, e.g., to check whether a liquid meets particular quality standards or safety norms. A lab technician receives a product sample, say of canal water, and will then proceed to measure the concentration of certain substances, for instance potassium ( $\mathrm{K}$ ions). This is typically done with advanced digital technology, a spectrophotometer (Fig. 1). He knows the measurement range of the spectrophotometer for this substance, because of prior experience or protocol information. When the concentration of potassium in the product sample is too high to be measured by the spectrophotometer, which is almost always the case, the lab technician dilutes the sample by a simple factor (e.g., 10 or 100) to make computation easy. It is important that he chooses a suitable combination of pipette and volumetric flask (e.g., a 5 -mL pipette and a volumetric flask of $50 \mathrm{~mL}$ ), so that the spectrophotometer can reliably measure the extinction in the range in which the calibration curve is linear (Fig. 2). The output of the spectrophotometer shows the extinction value and the concentration of the potassium in the diluted liquid (at a concentration of for instance $4.23 \mathrm{mg} / \mathrm{L}$ ). To determine the concentration in the original sample, the lab technician has to multiply the concentration value in the dilution with the dilution factor $(4.23 \mathrm{mg} / \mathrm{L} \times 50 /$ $5=42.3 \mathrm{mg} / \mathrm{L}$ ). In many but certainly not all cases, spreadsheets are set up to release employees from computations, and standard operation procedures are available to explain how computations should be carried out.

What does this example tell us about the nature of measurement at work? We intend to illustrate two issues: its technology-mediated nature and the integration in larger activities that are typically perceived as belonging to other areas of mathematics or science, in this case arithmetic, data analysis and chemistry.

In this case, a complex scientific machine is used, a spectrophotometer, in which laser light with a particular wavelength penetrates the liquid. With the right wavelength, the extinction is a measure of the concentration. By means of a calibration graph (a regression line, a statistical technique), the extinction value is used to derive a concentration value that still has to be adjusted to the concentration of the original sample. This example illustrates a point for measurement at work, succinctly formulated by Steen (2003) more generally: workplace mathematics is elementary but sophisticated in use, whereas school mathematics is sophisticated but simple in use.

We also observed that lab technicians consider their measurements to be chemical, not mathematical. We have come to call this discrepancy the Janus-head (two-faced) nature of mathematics in workplaces: Where we as
Fig. 2 Computer screen with measurements from the spectrophotometer. At the top right a calibration line is automatically produced and the correlation coefficient computed (0.999964)

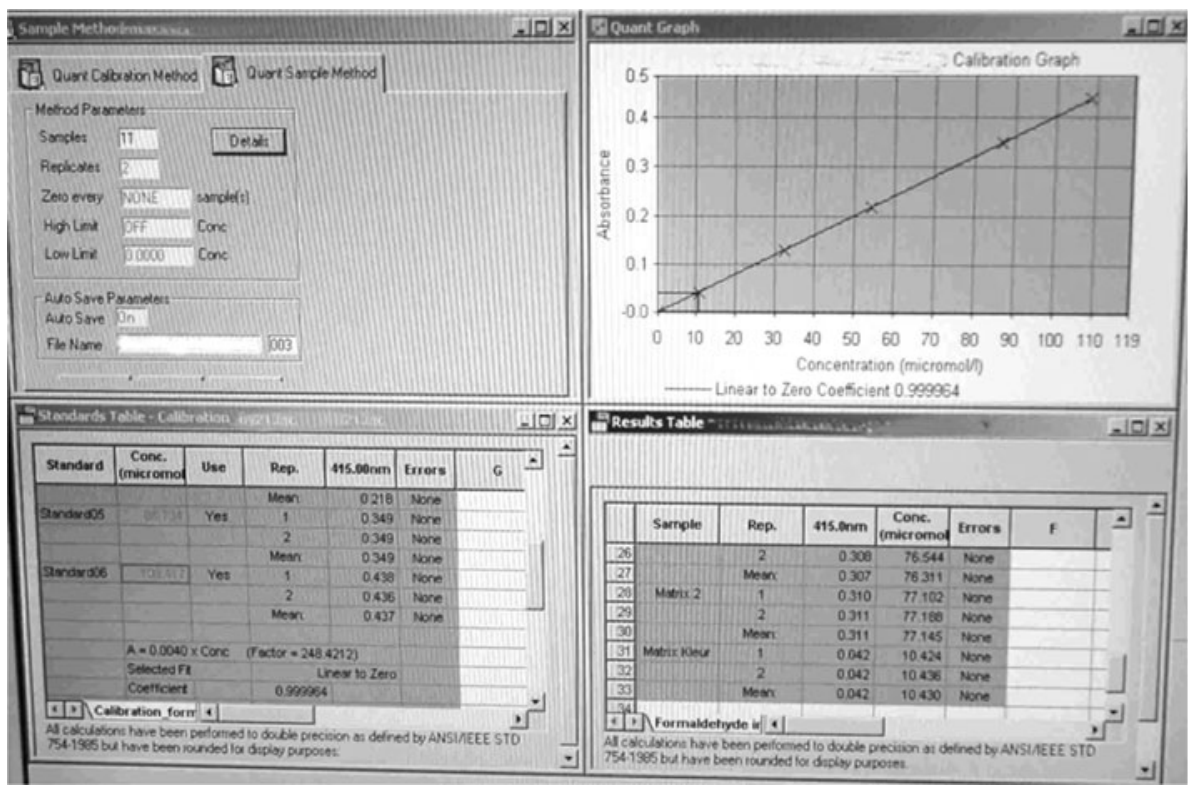


mathematics educators focused on the arithmetic (proportional reasoning) and statistics involved in this measurement activity, the lab technicians we interviewed argued they used no mathematics (cf. FitzSimons, 2002). They perceived their work as being chemical-determining the concentration of a chemical substance.

This perception can be understood when we frame measurement as an abstraction situated in a web of reasons (Bakker et al., 2008). As explained in the aforementioned measurement of concentrations in liquids, there are many reasons for doing things in particular ways. A scientific reason to dilute is to arrive at a concentration in the linear range of the spectrophotometer. Another scientific reason involved is to choose the right wavelength of the laser beam; otherwise, the wrong substance will be measured. However, as mathematics educators, we mainly saw the calibration graph that is made to derive the concentration of the dilution, the correlation coefficient telling how well the regression line fitted the measurement values, and the proportions at stake (mostly multiplication by ten) to infer the original concentration. This multiplication is simple, as lab technicians emphasized, but the web of reasons involved requires them to have integrated knowledge of the whole situation, including the standard operating procedures and what their colleagues know about measurement procedures. In such situations, we should consider measurement to be the domain of both mathematics and science.

\subsection{Measurement of refraction by opticians}

One competence description from the qualification file states: "The optician operates the focimeter in the right way to measure the glasses for the right refraction." The

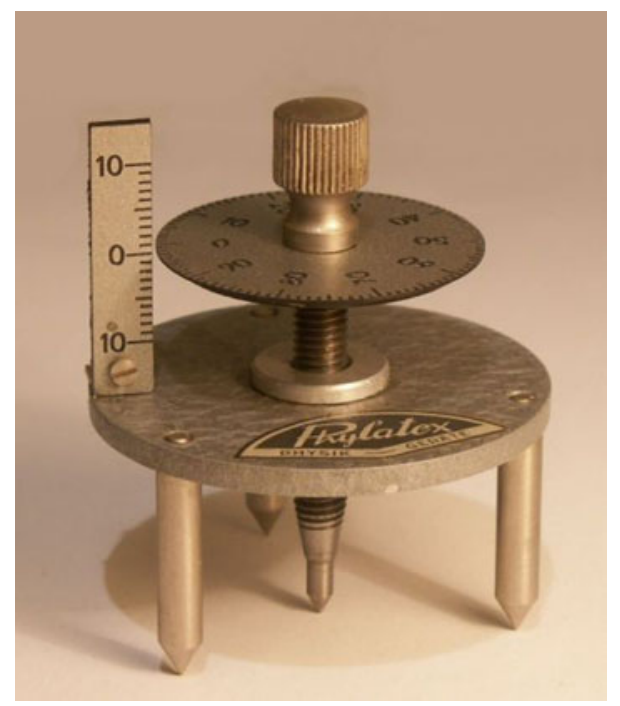

Fig. 3 Spherometer for measuring the curvature of lenses

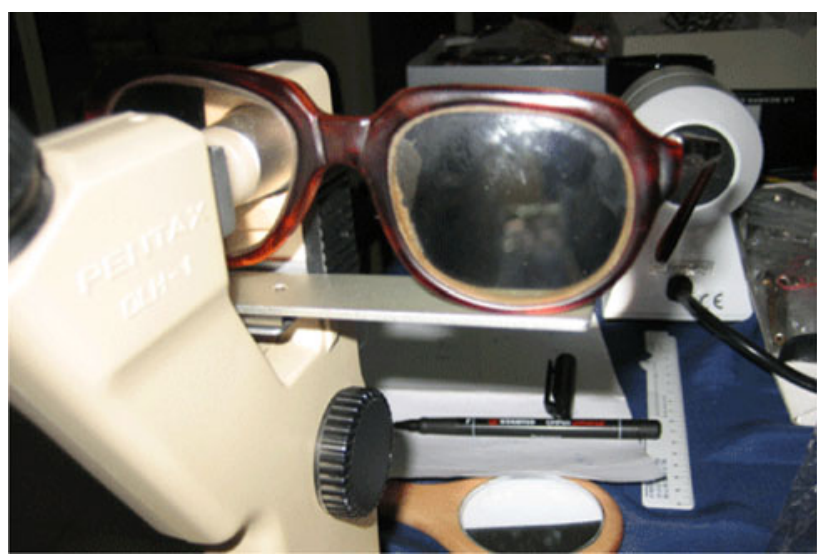

Fig. 4 Focimeter for measuring the refraction of glasses

purpose of this measurement is to compare the current state of the eyes of the client with the power of the lenses in the glasses. The accompanying core task of the optician indicates that several measurements are required to determine refraction: eye pressure, eye distances, and correction values. Next, they need to interpret the measurement values and prescribe the right refraction for glasses or contact lenses. All six work processes in this core task include a variety of measurement-related terms. Measurements are made using technical measurement devices, mostly digital technologies. Another core task involves polishing and faceting the glasses-manual craftwork involving measurement.

In the past, opticians used a spherometer (Fig. 3) to measure the curvature of the surface of lenses. The usual spherometer consists of a fine screw moving in a nut carried on the center of a small three-legged table or frame; the feet form the vertices of an equilateral triangle. Resulting measurements are used as the basis for computations from which the power of the lens can be derived. This illustrates the point made by Crosby (1997) that measurement leads to numbers and that mathematics (and in this case physics) can assist in manipulating these numbers. However, the spherometer is rarely used in opticians' shops nowadays. Instead, its modern successor, the focimeter, is used (see Fig. 4). It measures both the sphere and cylinder components of power of the lens in an electronic way. This hardly ever leads to mistakes in the refraction of the glasses prepared for clients.

\section{Conclusions}

In this paper we asked, What are the use, nature and purposes of measurement in intermediate-level occupations? Here, we summarize an answer to this question and speculate on some implications for education. 


\subsection{Use}

Measurement is used a lot in many occupations, especially in the technology and engineering sector. Within the care and welfare sector, the highest numbers of measurementrelated competence descriptions are found in the technical care occupations such as lab technicians and assistants of doctors, dentists and pharmacists. Within the business and economics sector, the majority of measurement-related competence descriptions are found in fashion, interior, carpet and textile-related occupations (at lower levels). To our surprise, measurement was mentioned least frequently in the agriculture, food and fisheries sector.

Though our analysis provides an overview that we have not found in the literature, there are inevitably limitations to this approach: Mathematics in the workplace often stays rather implicit (Straesser, 2000) and thus measurementrelated terms might not be mentioned even when measurement is used in an occupation. For example, the competence descriptions for an $\mathrm{MBO}$ nurse (regular nurses have training in higher professional education, $\mathrm{HBO}$ ) do not contain measurement-related terms even though one of the core tasks includes administering medication, oxygen, and intravenous infusion, which involves reading off values. From our knowledge of the occupation, we know that measurement is involved, e.g., when weighing babies and keeping score of fluids going in and out to monitor their liquid balance. Likewise hairdressers sometimes need to prepare particular amounts of hydrogen peroxide for bleaching hair, and bakers need to weigh and measure quantities of ingredients.

\subsection{Nature}

In our investigation of the nature of measurement, we focused on the tools used and the relation to areas of mathematics or other disciplines. Measurement is always mediated by tools. It may seem that workplaces always use modern digital machines that are often too expensive for schools, such as the large analyzers found in laboratories that can determine concentrations of more than a hundred samples in one run. However, in the oil refineries, digital technologies are rarely used because electricity is dangerous near the production of oil. Here employees typically work with old mechanical machines.

Measurement leads to numbers, which can then be used for computation or data analysis, which shows its intricate relationship to arithmetic and statistics. Measurement is also central in design and assembly, where its link to geometry transpires. In fact, geometry has its origin in measuring land (Dilke, 1987). In many cases, workplace supervisors considered measurement to be part of science rather than of mathematics, e.g., when determining the concentration of chemical substances in laboratories. This observation points to the Janus-head (two-faced) nature of measurement in work situations: From our perspective, measurement might seem mathematical, but for employees it is often not.

\subsection{Purposes}

Measurement at intermediate-level work is most often done to ensure quality of products and monitor processes and their efficiency and effectiveness. It is further used to make something fit (design, furniture, assembly), to solve problems and to ensure safety. Measurement can serve several purposes at the same time, because it leads to numbers that can be used for multiple purposes (e.g., quality, monitor, safety).

When measuring, it is important to know for what purpose the resulting numbers will be used. It will depend on the purpose how precise the measurements need to be and how often they need to be taken. Moreover, in workplace situations, it can make a huge difference whether a product is too big or too small: When making something fit, one condition might lead to scrap whereas the other would still lead to usable products. This illustrates the situated nature of measurement at work.

\subsection{Educational implications}

Formulating educational implications from workplace mathematical studies is never straightforward. School prepares not only for work, but also for citizenship and higher education. The educational implications we draw here are therefore only tentative.

The analysis of formalized descriptions of competencies revealed that measurement is used a lot in different occupations and for many different purposes. In addition, the qualitative study of measurement in two different occupations revealed that it is often implicit in actual work; furthermore, it is neither an isolated action nor purely mathematical. Rather, measurement is found to be embedded in a practice where areas of mathematics (and often science) are intertwined and where measurement processes are more and more mediated by digital technology. For this reason, Hoyles et al. (2010) have introduced the term techno-mathematical literacies for mathematical literacies situated in work contexts and mediated by digital technologies.

A first educational implication we want to formulate is that these features of workplace mathematics do not mean that school mathematics should mimic workplace mathematics but should prepare students for using mathematics at work. Both teachers and workplace supervisors in our studies stressed that students should understand what they 
are doing when it comes to measurement. In their view, this understanding can be promoted by developing disciplinary knowledge (e.g., optics, chemistry) underlying or related to measurement, and by using old-fashioned machines such as spherometers, which can show students the underlying principles that are not visible anymore in modern technology.

We contend that the task of education regarding mathematics in work can be conceptualized as a matter of opening up black boxes (cf. Williams \& Wake, 2007). Latour (1999, p. 304) pointed to the paradox of technology as black boxes:

scientific and technical work is made invisible by its own success. When a machine runs efficiently, ... one need focus only on its inputs and outputs and not on its internal complexity. Thus, paradoxically, the more science and technology succeed, the more opaque and obscure they become.

Education can aim to open up the black box of measurement at work. Using old-fashioned machines can be one of the means to illustrate the workings of more modern technologies and to talk about the scientific background (e.g., curvature of lenses). This allows students to learn how and why particular measurements are being conducted in a particular way.

A second implication for education relates to the point that measurement at work is unlikely to be purely mathematical. In the lab technician example, the context was mainly chemical, with measurement in the service of determining concentrations of substances. In the optician example, the context was mainly a physics one, with measurement of optical phenomena such as refraction. The Janus-head nature of measurement might lead to a situation where mathematics teachers only address simple forms of measurement without taking workplace contexts and norms into account, while science or workplace teachers do not consider it part of their job to teach measurement. There is thus a danger that measurement is not taught in its full complexity in either discipline.

Since measurement appears to be a natural link not only between mathematics and science (Lehrer, 2003), but also between mathematics and technical occupations, we contend that it can be exploited to help students see coherence not only between the different subjects (or areas within mathematics) but also between subject and occupation. This requires that measurement is not only taught as being an act of 'getting a number,' but also an act that has specific purposes and possible constraints (e.g., required and possible precision) imposed by the workplace. Furthermore, students should be stimulated to learn about the many connections that measurement has with arithmetic (see the lab technician example on proportional reasoning), geometry (making furniture fit), statistics (use of correlation and regression in the lab technician example), physics (the optician example), chemistry (lab example), etc. The second implication is therefore a call for careful coordination between teachers in different subject areas.

A third and last implication we consider worth expressing is that education about measurement at school should have a purpose that students can engage with. Occupations that appeal to students can offer inspiration for instructional design, a strategy used not only in secondary science education (e.g., Prins, Bulte, Pilot, \& Van Driel, 2009) and in statistics education (Dierdorp, Bakker, Eijkelhof, \& Van Maanen, 2011), but also in primary education. Konold and Lehrer (2008), e.g., used the idea of quality control in factories to develop data analysis skills in primary school students. Part of this investigative process involved measurement of 'fruit sausages,' cylindrical pieces of Play Dough that were to measure $5 \mathrm{~cm}$ in length and $1 \mathrm{~cm}$ in diameter. Konold and Lehrer claimed that this focus on measurement in an authentic quality control context helped students to identify sources of error, quantify measures of center and spread in natural ways, get to grips with scale and unit, which are all important aspects of measurement. The other implications we have formulated are in line with these studies on how to engage students in purposeful activity.

Because mathematics in general and measurement in particular is often implicit and invisible in work processes, there is a danger that school managers and teachers in vocational schools do not consider mathematics important and spend too little attention to it in the curriculum (or emphasize less important aspects of it). In fact, the teachers we interviewed often complained about this problem. This study might help in specifying and justifying particular educational objectives for measurement, an important aspect of intermediate-level work. We hope that this study of workplace measurement will help teachers and designers of mathematics, science and vocational education to consider how measurement can be used in realistic ways, how and when particular measurement tools should be used, and for what purposes.

Acknowledgments We thank the reviewers and guest editor Marja van den Heuvel-Panhuizen for their constructive comments and Nathalie Kuijpers for her editing help. Conversations with Koeno Gravemeijer on what employees should know about mathematics were also helpful. The contribution by Bakker, Wijers and Akkerman to the work reported here was funded by the Netherlands Organisation for Scientific Research under grant number PROO 411-06-205.

Open Access This article is distributed under the terms of the Creative Commons Attribution Noncommercial License which permits any noncommercial use, distribution, and reproduction in any medium, provided the original author(s) and source are credited. 


\section{References}

Adams, T. L., \& Harrell, G. (2003). Estimation at work. In D. H. Clements (Ed.), Learning and teaching measurement (pp. 229-244). Reston, VA: National Council of Teachers of Mathematics.

Bakker, A., Kent, P., Derry, J., Noss, R., \& Hoyles, C. (2008). Statistical inference at work: The case of statistical process control. Statistics Education Research Journal, 7(2), 130-145. http://www.stat.auckland.ac.nz/ iase/serj/SERJ7\%282\%29_ Bakker.pdf.

Bakker, A., Wijers, M., \& Akkerman, S. F. (2010). The influence of technology on what vocational students need to learn about statistics: The case of lab technicians. In C. Reading (Ed.), Data and context in statistics education: Towards an evidence-based society. Proceedings of the Eighth International Conference on Teaching Statistics (ICOTS8, July, 2010), Ljubljana, Slovenia. Voorburg, The Netherlands: International Statistical Institute. http://www.stat.auckland.ac.nz/ iase/publications/icots8/ ICOTS8_8I4_BAKKER.pdf.

Bright, G. W., Jordan, P. L., Malloy, C., \& Watanabe, T. (2005). Navigating through measurement in grades 6-8. Reston, VA: National Council of Teachers of Mathematics.

Cockcroft, W. (1982). Mathematics counts. Report of the Committee of Inquiry into the Teaching of Mathematics in Schools. London: Her Majesty's Stationery Office.

Creswell, J. (1998). Qualitative inquiry and research design: Choosing among five traditions. London: Sage Publications.

Crosby, A. W. (1997). The measure of reality. Quantification and Western society, 1250-1600. Cambridge: Cambridge University Press.

Dierdorp, A., Bakker, A., Eijkelhof, H. M. C., \& van Maanen, J. A. (2011). Authentic practices as contexts for learning to draw inferences beyond correlated data. Mathematical Thinking and Learning, 13, 132-151.

Dilke, O. A. W. (1987). Mathematics and measurement. London: British Museum.

FitzSimons, G. (2002). What counts as mathematics? Technologies of power in adult and vocational education. New York: Springer.

Greeno, J. G. (1998). The situativity of knowing, learning, and research. American Psychologist, 53, 5-26.

Hoyles, C., Noss, R., Kent, P., \& Bakker, A. (2010). Improving mathematics at work: The need for techno-mathematical literacies. London: Routledge.

Hutchins, E. (1995). Cognition in the wild. Cambridge, MA: MIT Press.

Kaiser, G., \& Willander, T. (2005). Development of mathematical literacy: Results of an empirical study. Teaching Mathematics and its Applications, 24(2\&3), 48-60.
Konold, C., \& Lehrer, R. (2008). Technology and mathematics education: An essay in honor of Jim Kaput. In L. D. English (Ed.), Handbook of international research in mathematics education (2nd ed.). New York: Routledge.

Latour, B. (1999). Pandora's hope: Essays on the reality of science studies. Cambridge, MA: Harvard University Press.

Lave, J. (1988). Cognition in practice: Mind mathematics and culture in everyday life. New York: Cambridge University Press.

Lehrer, R. (2003). Developing understanding of measurement. In J. Kilpatrick, W. G. Martin, \& D. E. Schifter (Eds.), A research companion to principles and standards for school mathematics (pp. 179-192). Reston, VA: National Council of Teachers of Mathematics.

Noss, R., \& Hoyles, C. (1996). Windows on mathematical meanings: Learning cultures and computers. Dordrecht, The Netherlands: Kluwer Academic Publishers.

Nunes, T. A., Schliemann, D., \& Carraher, D. W. (1993). Street mathematics and school mathematics. Cambridge, UK: Cambridge University Press.

Prins, G. T., Bulte, A. M. W., van Driel, J. H., \& Pilot, A. (2009). Students' involvement in authentic modelling practices as contexts in chemistry education. Research in Science Education, 39, 681-700.

Smith, J. P., I. I. I. (1999). Tracking the mathematics of automobile production: Are schools failing to prepare students for work? American Education Research Journal, 36, 835-878.

Steen, L. A. (2003). Data, shapes, symbols: Achieving balance in school mathematics. In B. L. Madison \& L. A. Steen (Eds.), Quantitative literacy: Why literacy matters for schools and colleges. Washington, DC: The Mathematical Association of America.

Straesser, R. (2000). Mathematical means and models from vocational contexts. In A. Bessot \& R. Ridgway (Eds.), Education for mathematics in the workplace (pp. 65-80). Dordrecht, The Netherlands: Kluwer Academic Publishers.

Van den Berg, B., \& De Bruijn, E. (2009). Het glas vult zich. Kennis over vormgeving en effecten van competentiegericht beroepsonderwijs; een review. [The glass is filling: Knowledge about design and effects of Competence Based Education; report of a review]. Amsterdam/Den Bosch: Expertisecentrum Beroepsonderwijs (ECBO).

Van den Heuvel-Panhuizen, M. (2005). Can scientific research answer the 'what' question of mathematics education? Cambridge Journal of Education, 35, 35-53.

Williams, J., \& Wake, G. (2007). Black boxes in workplace mathematics. Educational Studies in Mathematics, 64, 317-344. 